

\section{DISCLAIMER}

This information was prepared as an account of work sponsored by an agency of the U.S. Government. Neither the U.S. Government nor any agency thereof, nor any of their employees, makes any warranty, expressed or implied, or assumes any legal liability or responsibility for the accuracy, completeness, or usefulness, of any information, apparatus, product, or process disclosed, or represents that its use would not infringe privately owned rights. References herein to any specific commercial product, process, or service by trade name, trade mark, manufacturer, or otherwise, does not necessarily constitute or imply its endorsement, recommendation, or favoring by the U.S. Government or any agency thereof. The views and opinions of authors expressed herein do not necessarily state or reflect those of the U.S. Government or any agency thereof. 
M3LW-18OR0404015

Revision 0

\title{
Summary Report on \\ Activation Energies of Harvested Boston Insulated Wire and Okonite Cable Materials
}

\author{
Robert Duckworth \\ Oak Ridge National Laboratory
}

May 2018

Prepared for the

U.S. Department of Energy Office of Nuclear Energy 


\section{Light Water Reactor Sustainability Program}

\section{Summary Report on \\ Activation Energies of Harvested Boston Insulated Wire and Okonite \\ Cable Materials}

M3LW-18OR0404015

Revision 0

May 2018

Approved by:

Gary L. Bell

Group Leader, Plasma Technology and Applications Group,

Fusion and Materials for Nuclear Systems Division, ORNL

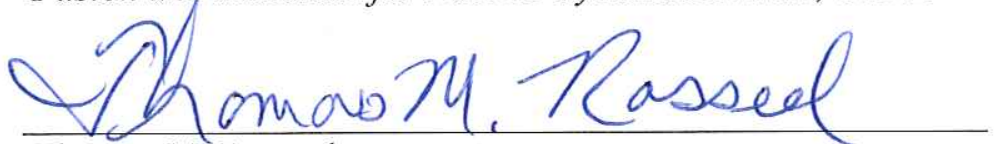

Thomas M. Rosseel

Materials Aging and Degradation, Deputy Pathway Lead

Light Water Reactor Sustainability Program

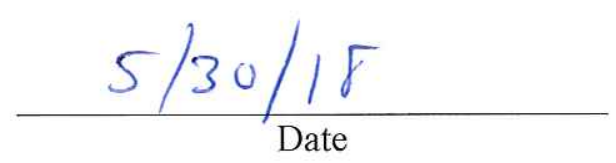




\section{SUMMARY}

As part of the Cable Aging Task within the Material Aging and Degradation (MAaD) pathway of the DOE Light Water Reactor Sustainability (LWRS) program, ORNL is collaborating with Pacific Northwest National Laboratory (PNNL), the Electric Power Research institute (EPRI), and the US Nuclear Regulatory Commission (NRC) to study cable aging mechanisms. Understanding cable aging mechanisms in cable insulation and jacket material of power and instrument and controls $(I \& \mathrm{C})$ cables will provide existing nuclear power plants (NPPs) with needed information as they seek plant life extensions to 80 years of operations.

This report summarizes activities in the characterization of harvested electrical $1 \& C$ cables related to activation energy and their role in determining the remaining margin of time cable insulation in NPPs can be used. Activation energy is the amount of energy that is required to break chemical bonds in a polymer through an endothermic reaction. For $I \& C$ cables that are utilized in NPPS, activation energy is used with a time and temperature dependent cable property like elongation at break (EAB) and/or an electrical property like voltage withstand to determine whether a cable insulation material meets the performance requirements for the environmental conditions such as temperature, radiation, and humidity for a given plant location. Considering differences in activation energies that were observed in harvested cable jackets when compared to previous measurements, an assessment of the cable insulation activation energy in harvested $1 \& C$ cables was performed given that the insulation performance ultimately determines the lifetime performance for a cable.

This assessment consisted of the mechanical and chemical characterization of harvested Boston Insulated Wire (BIW) and Okonite cable insulations from Zion NPP from a series of thermal accelerated aging exposures between $140^{\circ} \mathrm{C}$ and $160^{\circ} \mathrm{C}$. Cables were obtained as part of the LWRS Zion Harvesting Project in cooperation with Energy Solutions and the NRC. Activation energies of $1.10 \mathrm{eV}$ and $0.61 \mathrm{eV}$ were obtained for BIW and Okonite manufactured ethylene propylene rubber (EPR) insulation with individual chlorosulfonated polyethylene(CSPE) jackets respectively. When compared to previous measurements, the activation energy of BIW agreed well, while there was a sizeable gap for previous Okonite activation energies near $0.91 \mathrm{eV}$. The lack of agreement could be attributed to differences in raw materials used in a given insulation and/or jacket, differences in the thicknesses of the EPR insulation and CSPE individual jacket or the environmental conditions that the insulation from previous measurements experienced prior to characterization especially if cables were not stored at manufacturer recommended conditions. Comparison of harvested insulation compositions from multiple NPP sites and locations in a given NPP with respect to activation energy could provide some guidance on property sensitivity and insulation variations.

To address the issue of material thickness, an initial assessment of the influence of the CPSE individual jacket was also done. This was motivated by the different combinations of EPR insulation and CSPE individual jacket thicknesses that were found in harvested cables and previous measurements. Accelerated thermal aging of BIW-manufactured EPR insulation with individual CSPE jackets removed did show that the CSPE layer affected insulation degradation, further comparison of the compositional makeup of the CSPE and EPR for both BIW and Okonite insulation, along with a limited amount of additional accelerated aging, is needed to increase the level of confidence regarding the influence of the CSPE. 


\section{CONTENTS}

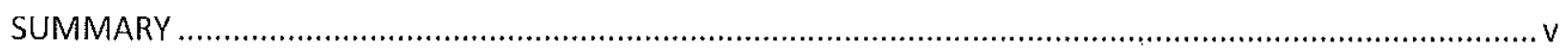

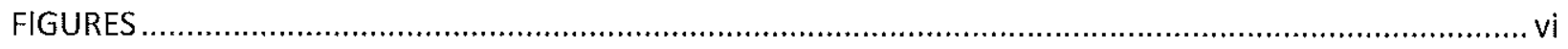

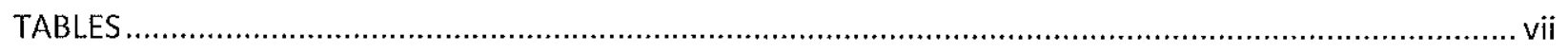

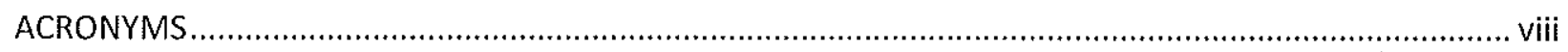

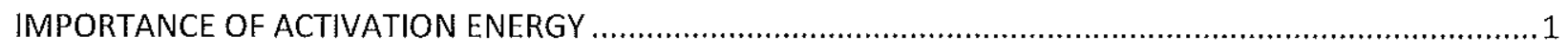

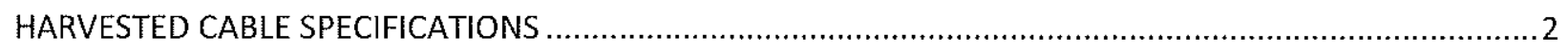

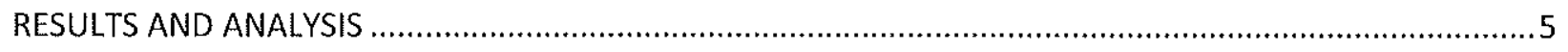

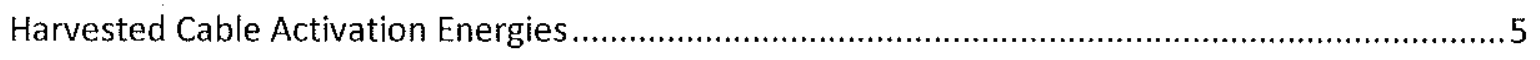

Role of CSPE in Accelerated Aging of BIW CSPE/EPR Insulation.............................................. 8

Impact of Accelerated Aging on Other Cable Insulation Properties ............................................9

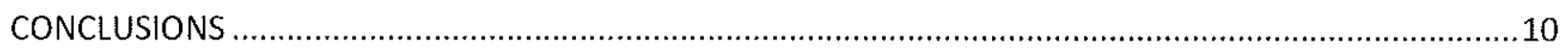

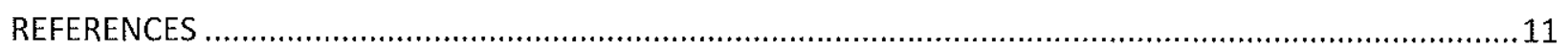

FIGURES

Fig. 1. $E A B$ as a function of temperature and time that was taken from $E Q$ documentation for a BIW manufactured cable with EPR/CSPE insulated

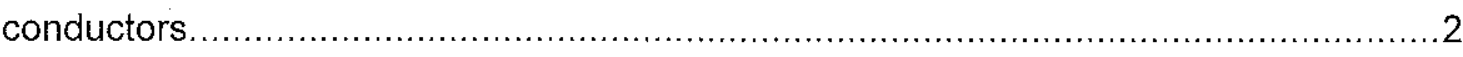

Fig. 2. Constant, $A_{T}$, as a function of inverse temperature for a BIW manufactured cable

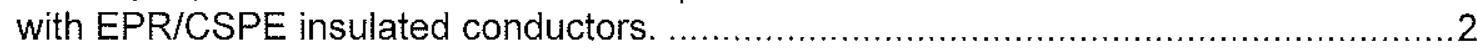

Fig. 3. Cross sections of insulated conductor from BIW cable that was harvested from Zion NPP.

Fig. 4. Cross sections of insulated conductor from Okonite cable that was harvested from Zion NPP.

Fig. 5. Cross sections of insulated conductor from BIW cable that was harvested from

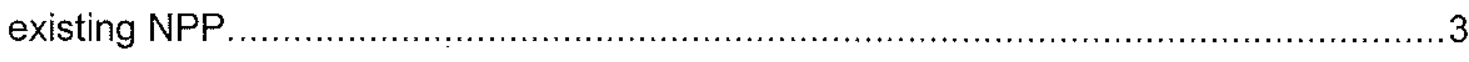

Fig. 6. Insulation sample arrangement utilized for accelerated thermal aging ........................4

Fig. 7. Example of EAB fixture utilized for mechanical strength measurement of harvested, aged cable insulation. ........................................................... 4

Fig. 8. Setup utilized in Archimedes density measurement. .......................................... 4

Fig. 9. EAB as a function of temperature and time for harvested BIW (BIW-A \& BIW-B) and Okonite manufactured CSPE/EPR cable insulations. 
Fig. 10. Comparison of EAB for harvested BIW (BIW-A \& BIW-B) cable insulations to $E A B$ data from BIW EQ documentation in Fig. 1.

Fig. 11. EAB cable insulation data for BIW-B and Okonite from Fig. 9 except time multiplied by a constant, $A_{T}$, at $160^{\circ} \mathrm{C}$ and $150^{\circ} \mathrm{C}$ respectively until overlap to reference temperature $E A B$ data occurs

Fig. 12. Constants $A_{T}$ with respect to inverse temperature for BIW-B and Okonite cable insulation.

Fig. 13. EAB cable insulation data for BIW-A \& BIW-B with a limited number of cases with the outer CSPE covering removed for the BIW-A.

Fig. 14. Constants $A_{T}$ with respect to inverse temperature for BIW-A (no CSPE), BIW-B and Okonite cable insulation.

Fig. 15. EAB and indenter modulus cable insulation data for BIW-A with and without the outer CSPE covering removed for the BIW-A.

Fig. 16. EAB and density cable insulation data for BIW-A with and without the outer CSPE covering removed for the BIW-A.

Fig. 17. FTIR spectra for BIW-A CSPE covering as a function of time for accelerated aging at $150^{\circ} \mathrm{C}$.

Fig. 18. FTIR spectra for BIW-A inner EPR covering as a function of time for accelerated aging at $150^{\circ} \mathrm{C}$

\section{TABLES}

Table 1. Designation and composition of harvested cable insulations presented in this report.

Table 2. Comparison of mechanical and electrical performance limit as measured by time to $10 \% \mathrm{EAB}$ and time to failure at $2 \mathrm{kV}$ electrical withstand from BIW EQ documentation [1]. 


\section{ACRONYMS}

$\begin{array}{ll}\text { BIW } & \text { Boston Insulated Wire } \\ \text { CSPE } & \text { Chlorosulfonated Polyethylene } \\ \text { DOE } & \text { Department of Energy } \\ \text { EAB } & \text { Elongation at Break } \\ \text { EPR } & \text { Ethylene Propylene Rubber } \\ \text { EPRI } & \text { Electrical Power Research Institute } \\ \text { EQ } & \text { Environmental Qualification } \\ \text { I\&C } & \text { Instrumentation and Control } \\ \text { LWRS } & \text { Light Water Reactor and Sustainability } \\ \text { NPP } & \text { Nuclear Power Plant } \\ \text { NRC } & \text { Nuclear Regulatory Commission } \\ \text { OKO } & \text { Okonite } \\ \text { SLR } & \text { Second (or Subsequent) License Renewal }\end{array}$




\section{IMPORTANCE OF ACTIVATION ENERGY}

Activation energy, $E_{\alpha}$, is utilized in environmental qualification (EQ) documentation for nuclear power plants (NPPS) to estimate the long-term performance of power, instrumentation, and control cable insulations relative to specified exposures of temperature, dose, and humidity. This estimate is based on pairing activation energy with a trackable property such as elongation at break (EAB) and/or dielectric breakdown strength to determine whether the cable insulation could reach the minimum 40 year threshold that NPPs had to meet for their first license. As NPPs operated during this period, cable assessments and their operating conditions by NPPs and organizations such as Electric Power Research Institute (EPRI), the US Department of Energy (DOE), and the US Nuclear Regulatory Commission (NRC) indicated that with active monitoring, sufficient margin in the cable insulation was present to support continued operation for another 20 years, otherwise known as first license renewal. With NPPS considering a second 20-year operating extension, second license renewal (SLR), as indicated by recent applications from Turkey Point, evaluation of the margin in harvested cables relative to properties like activation energy is needed to determine the extent of potential cable replacements or whether current active monitoring is sufficient to maintain safe NPP operation.

For the purposes of this report, activation energy is the amount of energy that is required to break chemical bonds in a polymer through an endothermic reaction. It is determined through accelerated aging of representative insulations at a minimum of three temperatures with respect to time and measuring a trackable property, which most often is EAB. Figure 1 shows EAB data for a Boston Insulated Wire (BIW) insulated cable that was obtained from the EQ documentation from Zion NPP [1]. The insulation was composed of a $0.76 \mathrm{~mm}$ thick inner ethylene propylene rubber (EPR) layer and a $0.38 \mathrm{~mm}$ thick individual chlorosulfonated polyethylene (CSPE) jacket. Assuming that the rate of degradation for the insulation follows an Arrhenius approximation, the dependence of the degradation with respect to time and temperature can be expressed as

$$
t_{1}=t_{2} \exp \left[\frac{E_{u}}{k}\left(\frac{1}{T_{1}}-\frac{1}{T_{2}}\right)\right]
$$

The variables $t_{1}$ and $T_{1}$ represent a reference time and temperature where the insulation degradation is a specific value of $E A B$, and $t_{2}$ and $T_{2}$ represent a different time and temperature where the insulation degradation reaches the same value. The constant, $k$, is the Boltzmann constant and has a value of $8.617 \times 10^{-5} \mathrm{eV} / \mathrm{K}$. Taking advantage of the exponential dependence of Equation (1) with respect to activation energy, time at a fixed temperature is multiplied by a constant, $A_{T}$, until the degradation 
dependence overlaps, and the constant is plotted on a log plot with respect to inverse temperature (Fig. 2) to determine the activation energy from the slope shown in Fig. 2. From the slope, activation energy was estimated to be $1.141 \mathrm{eV}$.

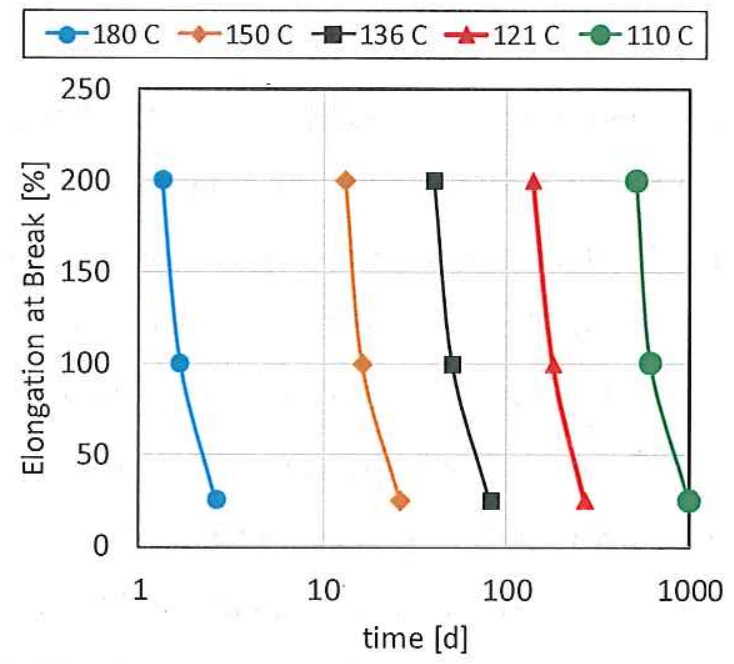

Fig. 1. $E A B$ as a function of temperature and time that was taken from EQ documentation for a BIW manufactured cable with EPR/CSPE insulated conductors.

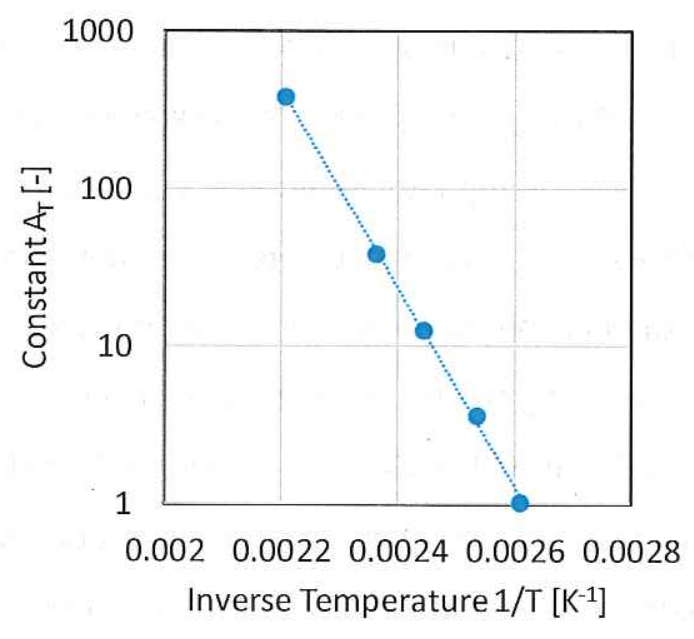

Fig. 2. Constant, $A_{T}$, as a function of inverse temperature for a BIW manufactured cable with EPR/CSPE insulated conductors. Constants found by multiplying time to degradation at a given temperature by the same value until data overlapped reference temperature of $110^{\circ} \mathrm{C}\left(\mathrm{A}_{\mathrm{T}}=1\right)$.

When the activation energy was measured in harvested cable outer protective jackets and compared to previous data, a decrease in activation energy was observed in a limited number of cases [2]. When the observed percentage of difference was applied to insulation, the insulation life could be reduced by 6 years. Given that the margin for a given insulation system is established by the insulation properties and not the outer protective jacket, measurement of the insulation activation energy in harvested cables used to estimate the remaining margin and determine if any observed degradation is consistent with expectations informed by EQ documentation.

\section{HARVESTED CABLE SPECIFICATIONS}

Accelerated aging and supporting measurements to determine activation energy were carried out on cables that were harvested from the Zion NPP. Cables were obtained as part of the Light Water Reactor and Sustainability (LWRS) Zion Harvesting Project in cooperation with Energy Solutions and the NRC. Zion NPP was in operation for 25 years prior to decommissioning before its 40 year operation license had 
expired. The harvested cables were from lower level containment areas outside of the middle barrier and were related to plant instrumentation and valve operation. Of the harvested cables from Zion, two cable manufacturers, BIW and Okonite, were selected for characterization based on their high degree of relevance to cables currently in use in the US NPP fleet. The insulation used in both types of cable consisted of an EPR insulation and individual CSPE jacket. Historically CSPE is used in cable insulation and construction to reduce flammability [3]. The first cable was a BIW-manufactured two-conductor cable in which each conductor was insulated with an inner EPR layer $1.0 \mathrm{~mm}$ thick and an outer CSPE $0.1 \mathrm{~mm}$ thick (Fig. 3). The second cable was an Okonite two-conductor cable in which each conductor was insulated with an inner EPR layer $1.4 \mathrm{~mm}$ thick and an outer CSPE layer $0.7 \mathrm{~mm}$ thick (Fig. 4). In addition, accelerated aging was carried out on similar BIW-manufactured cable that was obtained from an active NPP after 30 years of operation. The conductors of this multiconductor cable, 22 conductors total, were insulated with an inner EPR layer $1.1 \mathrm{~mm}$ thick and an outer CSPE layer $0.4 \mathrm{~mm}$ thick (Fig. 5). The inclusion of this third cable, and second type of BIW cable, was motivated by the thickness of the outer CSPE layer. Specifically, the harvested Zion BIW cable has a different CSPE thickness from what is originally listed in the EQ documentation. While this is likely due to differences in documentation and installation and limiting the number of cases examined, the use of a second BIW insulation from a second nuclear plant could provide some insight as to the impact of CSPE thickness on accelerated aging as well as a comparison of different types of BIW-manufactured cables. Table 1 provides the reference designations for the cables that are utilized in this report and summarizes cable insulation parameters for each.

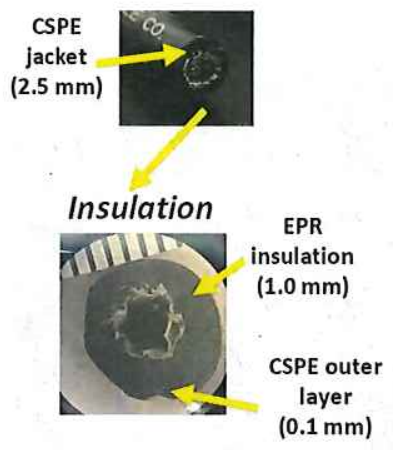

Fig. 3. Cross sections of insulated conductor from BIW cable that was harvested from Zion NPP. Results that are related to this cable are referenced as BIW-B in this report.

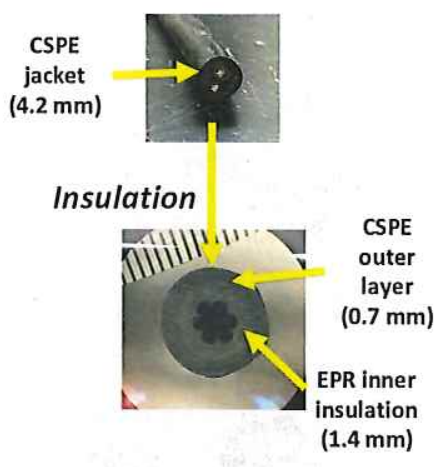

Fig. 4. Cross sections of insulated conductor from Okonite cable that was harvested from Zion NPP. Results that are related to this cable are referenced as OKO in this report.

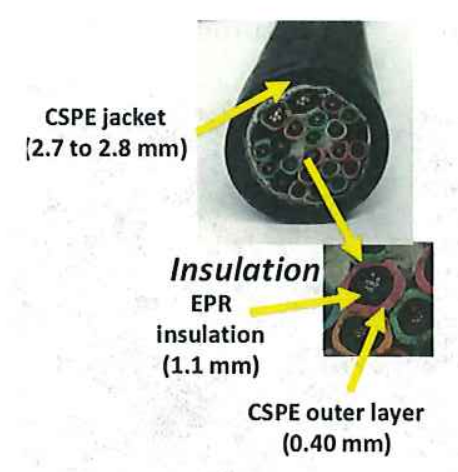

Fig. 5. Cross sections of insulated conductor from BIW cable that was harvested from existing NPP. Results that are related to this cable are referenced as BIW-A in this report. 
Table 1. Designation and composition of harvested cable insulations presented in this report.

\begin{tabular}{|c|c|c|c|c|}
\hline \multirow{2}{*}{ Designation } & \multicolumn{2}{|c|}{ Manufacturer } & Origin & $\begin{array}{c}\text { Inner EPR } \\
\text { Insulation } \\
\text { Thickness }\end{array}$ \\
\hline BIW-A & Boston Insulated Wire & Existing NPP & $1.1 \mathrm{~mm}$ & $\begin{array}{c}\text { Outer CSPE } \\
\text { Layer Thickness }\end{array}$ \\
\hline BIW-B & Boston Insulated Wire & Zion NPP & $1.0 \mathrm{~mm}$ & $0.1 \mathrm{~mm}$ \\
\hline BIW-EQ & Boston Insulated Wire & $\begin{array}{c}\text { Zion EQ } \\
\text { Documentation }\end{array}$ & $0.76 \mathrm{~mm}$ & $0.38 \mathrm{~mm}$ \\
\hline OKO & Okonite & Zion NPP & $1.4 \mathrm{~mm}$ & $0.7 \mathrm{~mm}$ \\
\hline
\end{tabular}

Accelerated aging was carried out on insulation samples that were harvested from each cable type as a function of temperature and time. A given cable insulation type was inserted into an air-circulation oven like the one shown in Fig. 6, and five to six samples were removed periodically to characterize their insulation properties with respect to time. The mechanical properties were measured via EAB and indenter modulus (Fig. 7) and chemical structure was measured via Fourier Transform Infrared Reflectometry (FTIR) and Archimedes density measurement (Fig. 8) [4]. In addition, accelerated aging was carried out on harvested cable insulation samples after the CSPE outer layer was removed. This was done to determine the influence of CSPE on accelerated aging and whether its presence significantly impacted initial degradation measurements with respect to temperature and time, which were significantly lower than the EQ documentation.

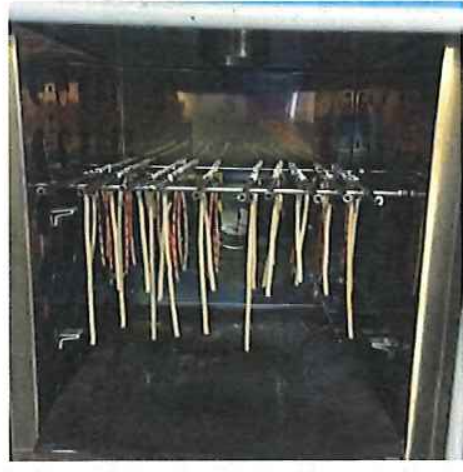

Fig. 6. Insulation sample arrangement utilized for accelerated thermal aging.

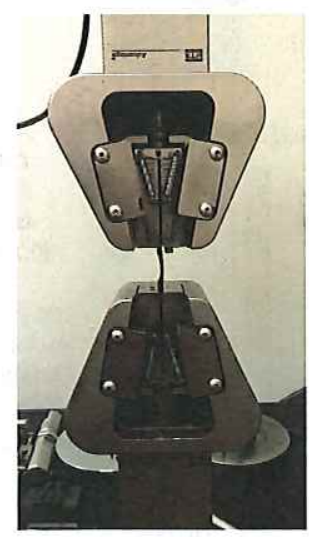

Fig. 7. Example of $E A B$ fixture utilized for mechanical strength measurement of harvested, aged cable insulation.

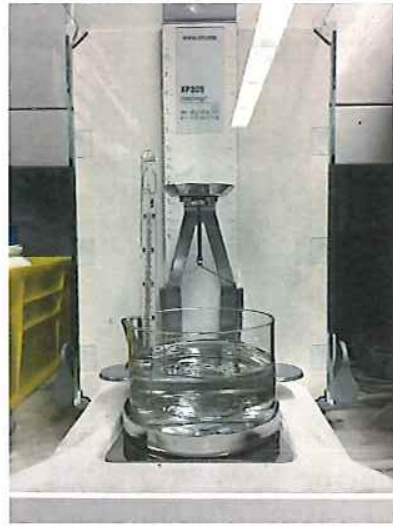

Fig. 8. Setup utilized in Archimedes density measurement. 


\section{RESULTS AND ANALYSIS \\ Harvested Cable Activation Energies}

The activation energy for the BIW and Okonite EPR/CSPE insulated conductors was estimated using EAB as a function of temperature and time as described in the first section of this report. Figure 9 shows the $E A B$ data as a function of temperature and time for each insulation type, and this data is compared to the EQ BIW data in Fig. 10. Compared to the original EQ data, all three insulation types show a measurable drop in $\mathrm{EAB}$ at a similar temperature. For example, 200\% $\mathrm{EAB}$ for $\mathrm{BIW}-\mathrm{B}$ is estimated to be 6.5 days at $150^{\circ} \mathrm{C}$ and 10 days at $140^{\circ} \mathrm{C}$, while the EQ documentation listed $200 \% \mathrm{EAB}$ as two to four times higher at similar temperatures -13.2 days at $150^{\circ} \mathrm{C}$ and 40 days at $140^{\circ} \mathrm{C}$. It is also interesting to note that the difference between BIW-B and Okonite for the two temperatures tested to date was lower than the EQ documentation. Using $140^{\circ} \mathrm{C}$ as the reference point to calculate the constant, $A_{T}$, for the $150^{\circ} \mathrm{C}$ data (Fig. 11) and plotting the constants as a function of inverse temperature (Fig. 12), activation energies of $1.10 \mathrm{eV}$ and $0.61 \mathrm{eV}$ were estimated for BIW-B and Okonite EPR/CSPE cable insulation, respectively. Despite the limited amount of data collected to date and the noticeably different insulation constructions for the BIW-manufactured cables, the value for BIW-B was remarkably close to the EQ documentation value. The lack of EQ documentation on Okonite EPR insulation with CSPE insulation jacket leaves the question of its activation energy an open question. When Sandia examined the activation energy of Okonite EPR insulation that did not have a CPSE individual jacket, a higher activation energy of $0.92 \mathrm{eV}$ was found [5]. Further work including removal of the CSPE jacket from Okonite as well as BIW manufactured EPR insulation with CSPE individual jackets and supporting aging and characterization should provide some insight on whether the lower activation energy is simply an artifact of the CSPE or other factors. 


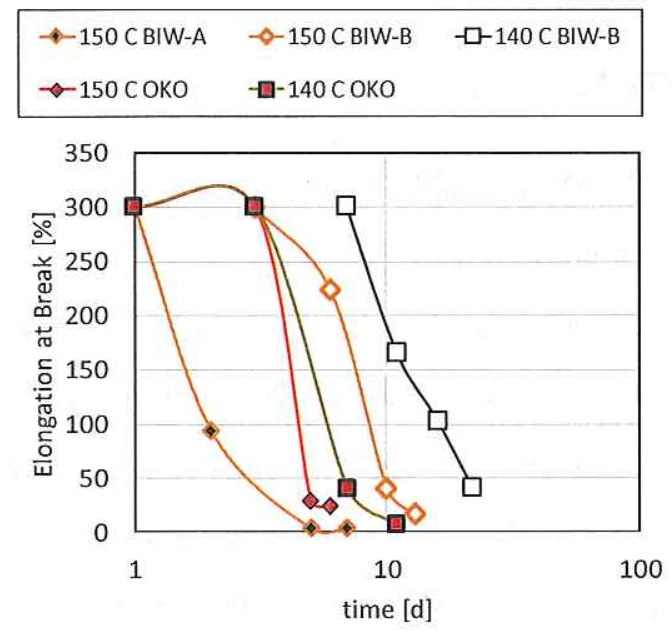

Fig. 9. $E A B$ as a function of temperature and time for harvested BIW (BIW-A \& BIW-B) and Okonite manufactured CSPE/EPR cable insulations.

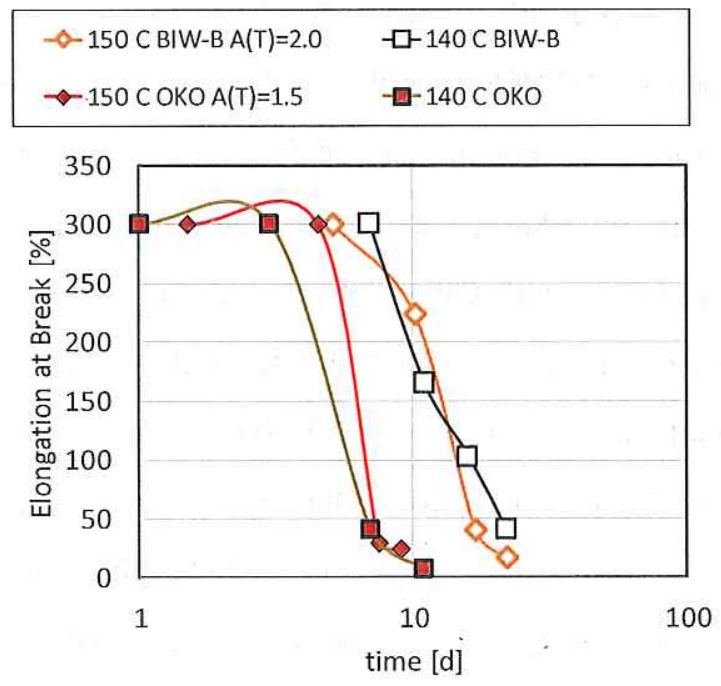

Fig. 11. EAB cable insulation data for BIW-B and Okonite from Fig. 9 except time multiplied by a constant, $\mathrm{AT}_{\mathrm{T}}$, at $160^{\circ} \mathrm{C}$ and $150^{\circ} \mathrm{C}$, respectively, until overlap to reference temperature EAB data occurs.

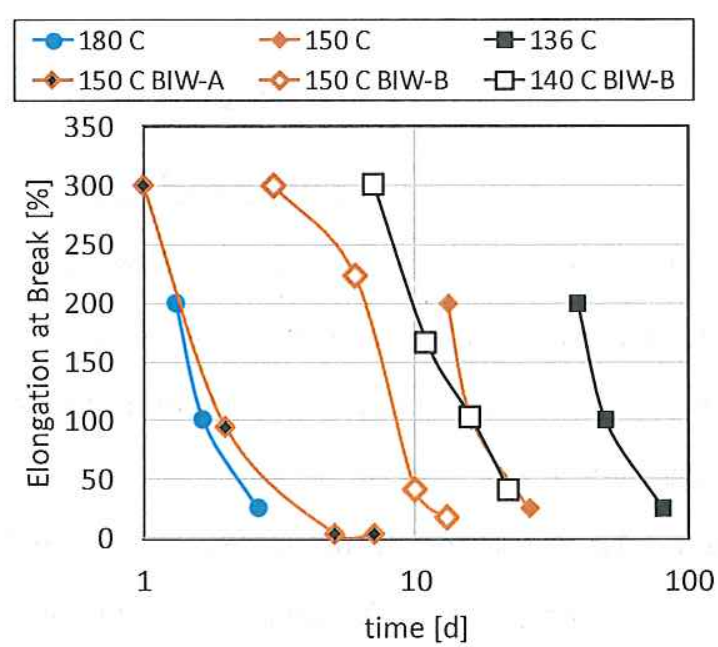

Fig. 10. Comparison of $E A B$ for harvested $B I W$ (BIW-A \& BIW-B) cable insulations to $E A B$ data from BIW EQ documentation in Fig. 1.

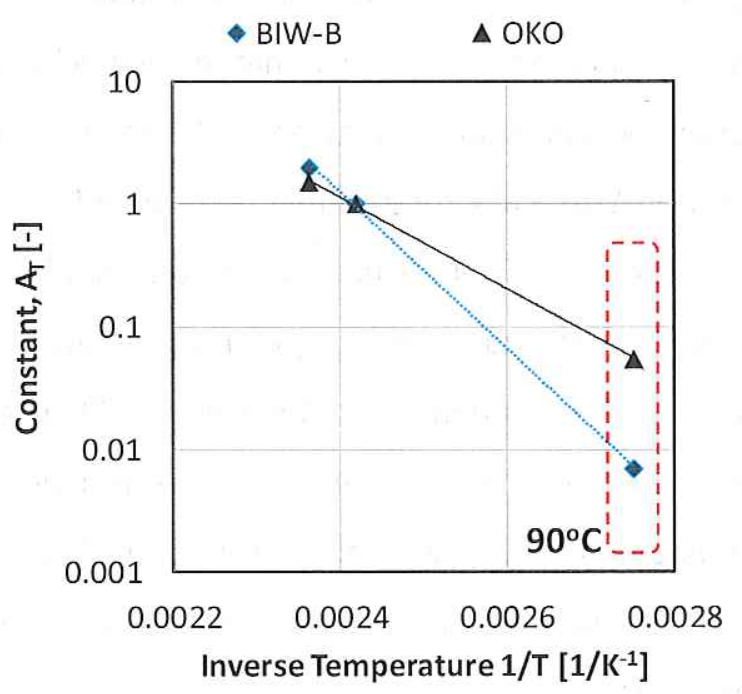

Fig. 12. Constant $A_{T}$ with respect to inverse temperature for BIW-B and Okonite cable insulation. Exponential curve fit, $\mathrm{e}^{-\mathrm{E}(\mathrm{a}) \mathrm{R} / \mathrm{T}}$, utilized to estimate activation energy and predict constant value at maximum operating temperature, $A_{T}\left(90^{\circ} \mathrm{C}\right)$.

The activation energy is only one part of the picture with respect to the cable insulation remaining useful life. Maximum operating temperature and the performance limit help to determine the remaining useful life. Selecting a maximum temperature of $90^{\circ} \mathrm{C}$, which is assumed in the EQ documentation presented earlier, the constant, $A_{T}$, is estimated from the exponential curve fit that is a function of activation energy. 
For BIW-B and Okonite, $A_{T}$ at $90^{\circ} \mathrm{C}$ was estimated to be 0.0549 and 0.0070 , respectively. This constant is multiplied by the time at the reference temperature of $140^{\circ} \mathrm{C}$ to reach the specified performance limit. The question then becomes what specified performance limit should be used.

In reviewing the EQ documentation for the BIW cable presented earlier, it would make sense that the electrical withstand as a function of temperature and time should be used as the performance limit. To provide some perspective on mechanical and electrical properties, Table 2 compares the time to $10 \% \mathrm{EAB}$ to the time to electrical withstand failure at $2200 \mathrm{~V}$ as a function of temperature. This electrical withstand failure was measured on cables after;

- they were aged at temperature as a function of time, and

- they were subjected to a representative loss-of-coolant accident (LOCA), and

- bent on a diameter 40 times the overall cable diameter.

As shown in Table 2, the time to electrical withstand was significantly higher, especially as the temperature dropped. If the time to failure with respect to electrical withstand at $136^{\circ} \mathrm{C}$ is estimated to be the time to failure at $140^{\circ} \mathrm{C}$ and using the constant found from the BIW activation energy measurement, $\mathrm{A}_{\mathrm{T}}\left(90^{\circ} \mathrm{C}\right)$ of 0.0070 , the time to electrical withstand at $90^{\circ} \mathrm{C}$ can be estimated to be 102 years. This analysis is only useful if the degradation of mechanical and electrical properties is related in harvested cables. Given the amount of cable required to essentially requalify the insulation through a LOCA scenario followed by an electrical withstand, degradation has focused on mechanical and chemical properties that are more readily obtained. Focused effort on the connection between electrical and mechanical properties as a function of temperature with a limited number of LOCA simulated exposures and supporting could provide cable aging managers and supporting organizations with better information as they determine cable conditions and remaining useful life.

Table 2. Comparison of mechanical and electrical performance limit as measured by time to $10 \%$ EAB and time to failure at $2 \mathrm{kV}$ electrical withstand from BIW EQ documentation [1].

\begin{tabular}{|c|c|c|}
\hline $\begin{array}{c}\text { Temperature } \\
{\left[{ }^{\circ} \mathrm{C}\right]}\end{array}$ & Time to 10\% EAB [hr] & $\begin{array}{c}\text { Time to failure when electrical withstand of } \mathbf{2 ~} \mathbf{k V} \text { is } \\
\text { applied after LOCA and } \mathbf{4 0} \text { times diameter bend [hr] }\end{array}$ \\
\hline $\mathbf{1 2 1}$ & 6620 & 17,780 \\
\hline $\mathbf{1 3 6}$ & 1100 & 6309 \\
\hline $\mathbf{1 5 0}$ & 551 & 1737 \\
\hline $\mathbf{1 8 0}$ & 206 & 251 \\
\hline
\end{tabular}




\section{Role of CSPE in Accelerated Aging of BIW CSPE/EPR Insulation}

Initially it was assumed that the differences in the CSPE and EPR thicknesses and their ratios could impact the activation energy presented earlier. This would appear not to be the case based on the similarities in activation energies of BIW-B and EQ documentation. However, when differences between BIW-A and BIW-B degradation were observed (Fig. 9), accelerated aging was carried out on BIW cable insulation with the CSPE insulation removed. Figure 13 shows the increase in EAB that was observed in BIW-A degradation after the CSPE insulation was removed. At the same temperature $\left(150^{\circ} \mathrm{C}\right)$, an increase in $\mathrm{EAB}$ by a factor of 20 was observed. When an activation energy analysis was carried out (Fig. 14), the activation energy for BIW-A without CSPE was estimated to be $1.51 \mathrm{eV}$. Additional accelerated aging is planned on BIW-A with and without CSPE at multiple temperatures and supporting EPR and CSPE elemental analysis is planned on all BIW-manufactured cable insulations to compare compositions and their impact on cable aging. This data will help determine how feasible it is to compare accelerated aging findings across different cable insulations within a given manufacturer.

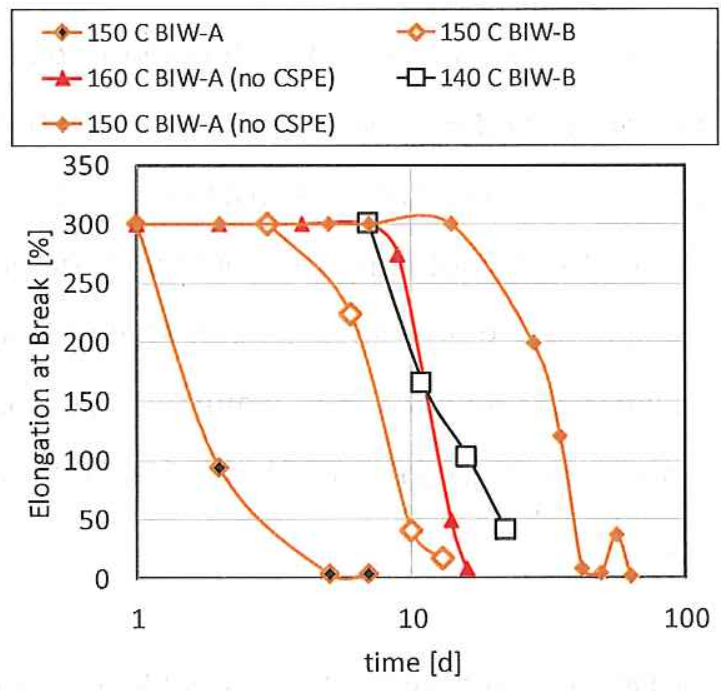

Fig. 13. EAB cable insulation data for BIW-A \& BIW-B with a limited number of cases with the outer CSPE covering removed for the BIW-A.

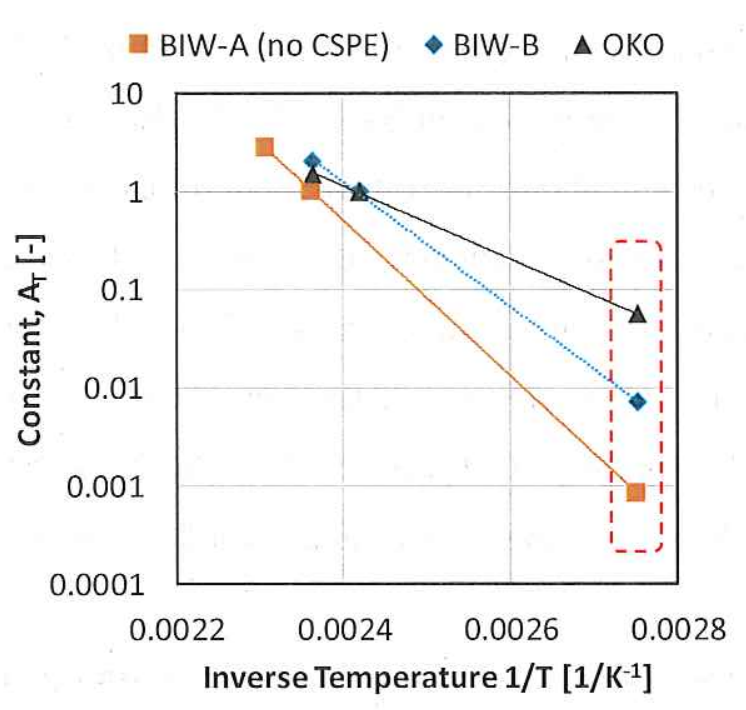

Fig. 14. Constants $A_{T}$ with respect to inverse temperature for BIW-A (no CSPE), BIW-B, and Okonite cable insulation. Exponential curve fit, $\mathrm{e}^{-E(\mathrm{a}) \mathrm{R} / \mathrm{T}}$, utilized to estimate activation energy and predict constant value at maximum operating temperature, $A_{T}\left(90^{\circ} \mathrm{C}\right)$. 


\section{Impact of Accelerated Aging on Other Cable Insulation Properties}

In addition to $E A B$, other cable insulation properties were systematically measured. These properties provide insight into degradation mechanisms and provide additional parameters that could be used to determine remaining useful life when the amount of cable insulation material is limited. Figure 15 shows the positive correlation between EAB and indenter modulus for BIW-A with and without CSPE. There appears to be an upward trend with respect to density (Fig. 16), but additional measurements are needed and are planned in the near term on all BIW and Okonite materials. Utilization of density would greatly increase the number of data points through the reduction of material that could be used to assess activation energy. Finally, Figs. 17 and 18 show examples of the FTIR spectra that have been collected on BIW-A CSPE and the inner EPR respectively at a given temperature. In both cases reduction in peaks are observed as oxidation occurs in the carboxyl groups near $2842 \mathrm{~cm}^{-1}$ and $2917 \mathrm{~cm}^{-1}$ as well as between 1600 $\mathrm{cm}^{-1}$ and $1800 \mathrm{~cm}^{-1}$. Additional reductions related to $\mathrm{C}-\mathrm{H}$ and possible fillers are observed between 800 $\mathrm{cm}^{-1}$ and $1100 \mathrm{~cm}^{-1}$. Further analysis of the filler composition relative to the FTIR spectra would be needed to resolve this specifically, but a trackable signal with aging does demonstrate the effectiveness of FTIR in assessment of cable aging life.

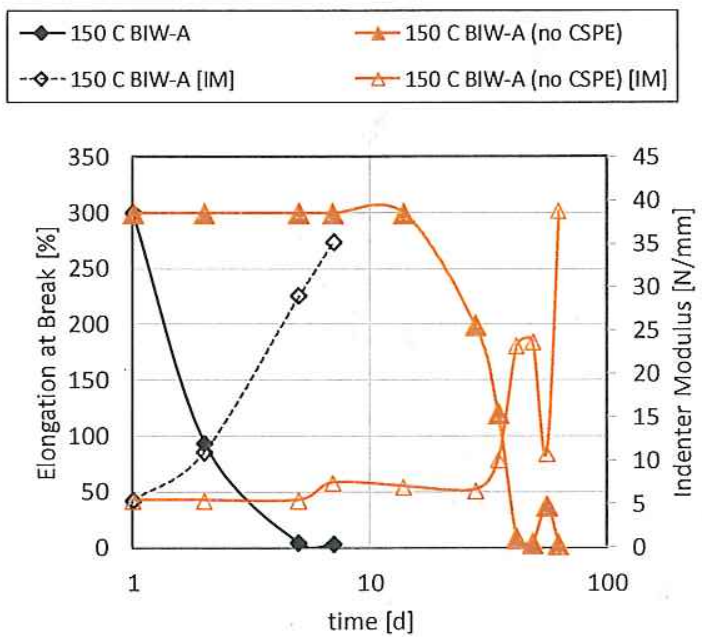

Fig. 15. $E A B$ and indenter modulus cable insulation data for BIW-A with and without the outer CSPE covering removed for the BIW-A.

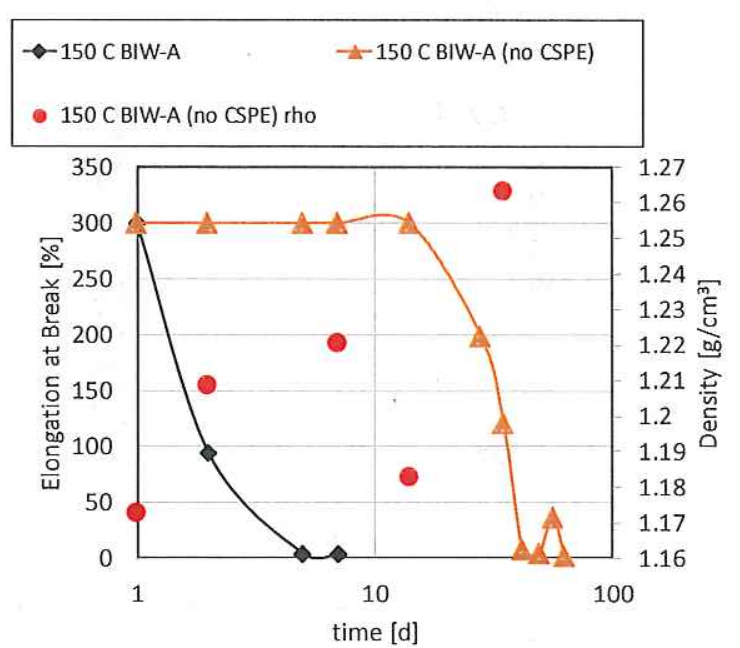

Fig. 16. EAB and density cable insulation data for BIW-A with and without the outer CSPE covering removed for the BIW-A. 


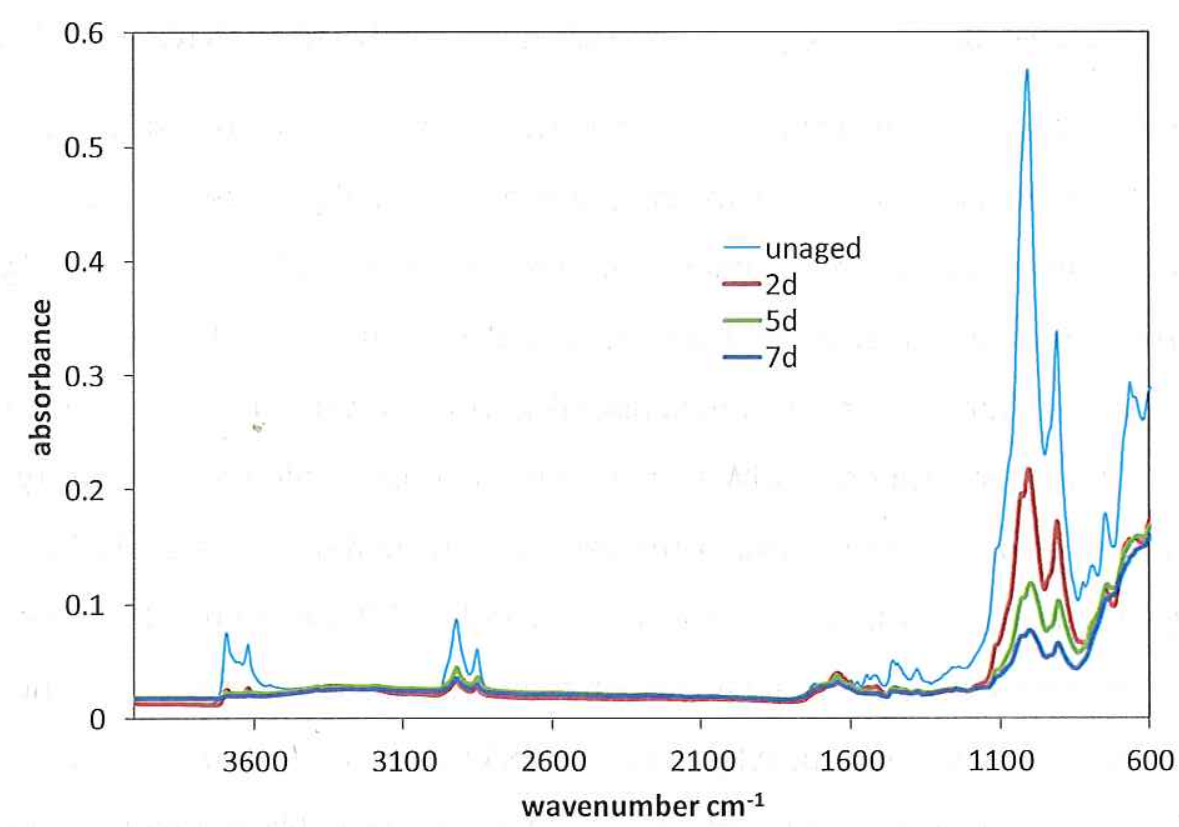

Fig. 17. FTIR spectra for BIW-A CSPE covering as a function of time for accelerated aging at $150^{\circ} \mathrm{C}$.

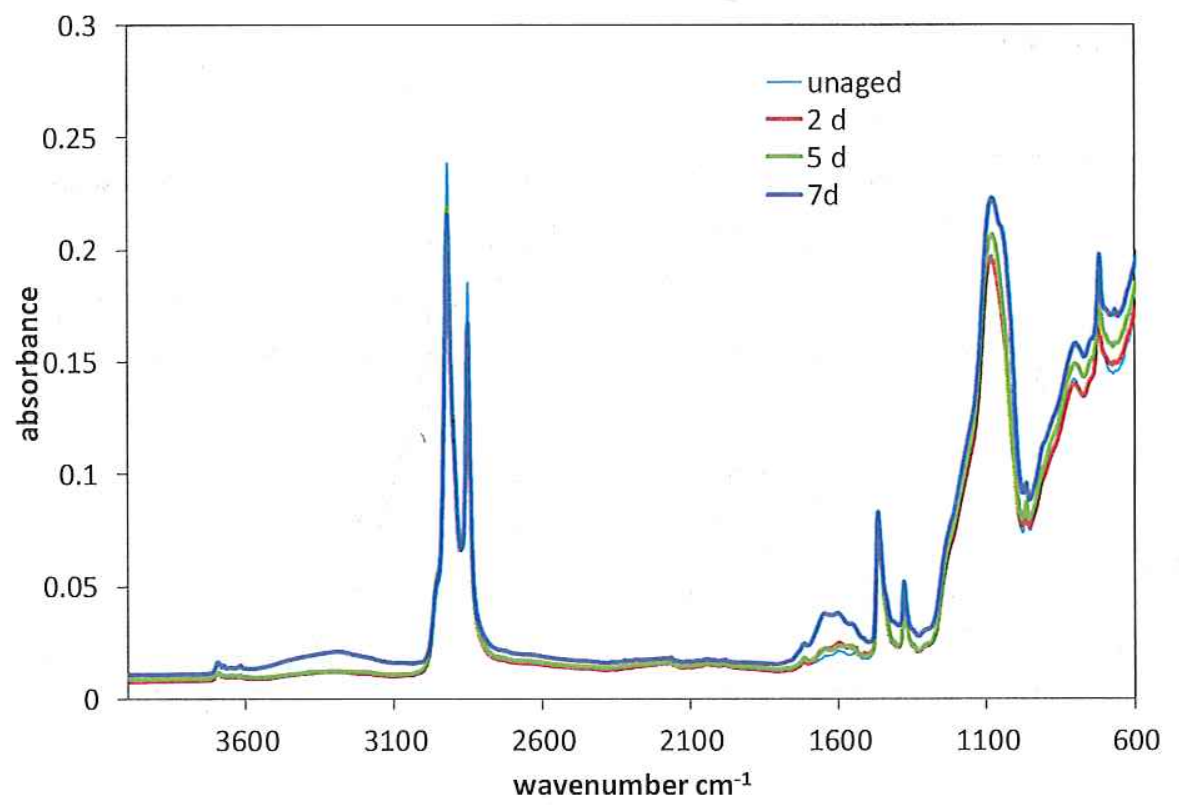

Fig. 18. FTIR spectra for BIW-A inner EPR covering as a function of time for accelerated aging at $150^{\circ} \mathrm{C}$.

\section{CONCLUSIONS}

Activation energies of $1.10 \mathrm{eV}$ and $0.61 \mathrm{eV}$ were obtained for BIW and Okonite manufactured EPR insulation with individual (CSPE) jackets respectively. When compared to previous measurements, the 
activation energy of BIW agreed well, while there was a sizeable gap for previous Okonite activation energies near $0.91 \mathrm{eV}$, which consisted of EPR insulation without CSPE. An initial assessment of the influence of the CPSE individual jacket was also done. Comparison of accelerated thermal aging of BIWmanufactured EPR insulation with and without the individual CSPE jacket removed did show that the CSPE layer affected insulation degradation. Further comparison of the compositional make-up of the CSPE and EPR for both BIW and Okonite insulation, along with a limited amount of additional accelerated aging, is needed to increase the level of confidence regarding the influence of the CSPE.

The utilization of activation energy to determine the remaining useful life in EPR insulation with individual CSPE jacket is limited to information available on electrical performance properties. Typically, the activation energy determines the rate of degradation with respect time and temperature and it is assumed that the mechanical and electrical properties are related, which is consistent with IEEE 323 and 383 standards for cable insulation. Utilizing the electrical withstand data from EQ documentation, it would predict that the remaining useful life is 100 years. However, a reduction in mechanical properties as measured by EAB was observed would suggest that there is likely a reduction in electrical performance. Further examination of electrical properties such as withstand and dielectric breakdown strength in harvested I\&C cables as well as accelerated aging in current $1 \& \mathrm{C}$ cables might provide insight as to the relationship between mechanical and electrical properties and establish guidance as to the remaining margin in harvested I\&C cables.

\section{REFERENCES}

1. Zion Station Equipment Qualification Binder, BIW Cable Systems Inc. Electrical Instrumentation, Control, Thermocouple Extension Cables, Sargent \& Lundy Engineers, EQ-ZN042 (1991).

2. R. Duckworth \& S. Davis, "Consequence of Activation Energy and Mechanical Properties in Harvested I\&C Cables," Transactions of the American Nuclear Society, vol. 117, pp. 650-652 (2017).

3. Cable Polymer Material Handbook - Low Voltage Power and Control Cable, EPRI, Palo Alto, CA, Report No. 3002010637 (2017).

4. K.T. Gillen, M. Celina, \& R.L. Cough, "Density measurements as a condition monitoring approach for following aging of nuclear power plant cable materials," Radiation Physics and Chemistry, vol. 56, pp. 429-447 (1999).

5. K.T. Gillen \& R. Bernstein, Review of Nuclear Power Plant Cable Aging Studies with Recommendations for Improved Approaches and for Future Work, Sandia National Laboratories, SAND-2010-7266 (2010). 
